\title{
Education in the age of COVID-19: Implications for the future
}

\author{
Paul Stanistreet ${ }^{1} \cdot$ Maren Elfert $^{2} \cdot$ David Atchoarena $^{1}$ \\ Published online: 2 June 2021 \\ (c) UNESCO Institute for Lifelong Learning and Springer Nature B.V. 2021
}

It is our pleasure to present our second double special issue on "Education in the age of COVID-19" to readers of the International Review of Education - Journal of Lifelong Learning (IRE). Its companion double special issue, compiled in December 2020, ${ }^{1}$ included 12 articles focused on the consequences of the pandemic and the national lockdowns prompted by its outbreak. It offered a snapshot of how the world was coming to terms with the educational challenges of the crisis. This second special issue features 10 more articles, which take the impact of the pandemic as a platform from which to examine what has happened, how societies have responded and how we might do better. It considers some of the social fractures and inequities exposed by the pandemic and shines a critical light on the role of different national and international actors. This issue concludes the work we began in March 2020 when we sent out a call for papers to which 150 researchers around the world responded. Our aim, at the time, was to understand the emerging impact of the pandemic on education. We had no idea how long the pandemic would last or what its consequences would be for teachers, students, institutions or wider society. However, we realised that how we responded to the challenges posed by the new reality in which we found ourselves would be critical to all our futures, and to the future of education in particular.

A year on, the situation remains surprisingly similar from an educational point of view. Many countries worldwide are still under lockdown measures that continue to

\footnotetext{
1 Stanistreet, P., Elfert, M., \& Atchoarena, D. (Eds) (2020). Education in the age of COVID-19: Understanding the consequences (double special issue). International Review of Education, 66:5-6. https:// link.springer.com/journal/11159/volumes-and-issues/66-5.
}

Paul Stanistreet

p.stanistreet@unesco.org

Maren Elfert

maren.elfert@kcl.ac.uk

David Atchoarena

d.atchoarena@unesco.org

1 UNESCO Institute for Lifelong Learning, Hamburg, Germany

2 King's College, London, United Kingdom 
have a dramatic impact on learners. School closures and the shift to online provision in higher, technical and adult education have significantly disrupted the learning of students around the globe. And while many providers have been able to respond creatively to these disruptions and maintain continuity of learning for their students, to one degree or another, many more have lacked the financial, technological and pedagogical resources to support their learners adequately through lockdown. The unequal impact of the pandemic, and its tendency to hit poorer and less-advantaged communities hardest, has prompted some overdue reflection on structural inequality and its impact on educational opportunity. It has made us think harder about the purposes of education and its status not merely as a private good but as a public one. It has also spurred reflection on the role of private, profit-led interests in education, and the need for resources to be made available on a fair, democratic, human-centred basis. Doubtless, the consequences of the pandemic and the new, critical thinking it has provoked will preoccupy educators for years, if not decades, to come.

The articles featured in this special issue aim to enhance our understanding of the consequences of the COVID-19 crisis for education worldwide and to inspire critical discussion of the educational implications of the pandemic, with a view to informing future actions. They include empirical and theoretically oriented contributions with a focus on adult and community education, schooling and higher education. As with the first special issue, there is a high number of co-authored articles. Of the ten articles included in this volume, only three are single-authored. Five have three authors or more, and all co-authored articles involve women. We see these examples of collaboration as a sign of hope in a society in which collaborative opportunities and experiences are scarce.

A central message of all the articles in this special issue is that the move to online learning has reinforced inequalities of access and participation in education, not only in schools and universities, but in adult education too. Two articles in this issue focus in particular on the impact of the pandemic on adult education. The first one of these is "Inventive pedagogies and social solidarity: The work of communitybased adult educators during COVID-19 in British Columbia, Canada", authored by three adult education scholars and activists from Canada. Suzanne Smythe, Amea Wilbur and Emily Hunter investigate the impact of the pandemic on the work of adult educators in low-income and newcomer communities in British Columbia. Their study, which is based on interviews with "frontline" community workers, provides many insights into the challenges and opportunities of community work during the COVID-19 crisis. While the study reveals that poor and marginalised communities have suffered greatly from the consequences of the pandemic, it also finds that the current situation has given rise to new opportunities. Due to inequalities in digital access, online provision has excluded many who relied on and are in need of community services; 20 per cent of students in community-based programmes did not return to their programmes after the shift to remote learning. However, in some cases, the reorganisation of some services also opened up opportunities for students. Adult educators developed a range of "inventive pedagogies" of solidarity, which can inspire community work in the future. They point to the possibility of more inclusive and equitable ways of combining community-based intervention and technology in the post-pandemic world. 
The second article that is of particular relevance to adult education is by a group of scholar-educators, Isaiah Zukowski, Zachary Parker, Daisy Shetterly and Kimberly Valle. "Public health crises compounded: A high school equivalency context in the time of a pandemic" presents an autoethnographic case study of their work as instructors in a non-profit high school equivalency (HSE) programme offering educational opportunities to disadvantaged adults and young people in Philadelphia during COVID-19. The article sheds important light on the challenges faced by a non-governmental organisation (NGO) already weakened by neoliberal policies in providing HSE diplomas, and on the impact of COVID-19 on marginalised youth long living in crisis in the United States. Minority communities, the article finds, have been particularly affected by increasing rates of traumatic stress, housing and food insecurity, and domestic violence, along with higher rates of COVID-19. The article aptly concludes with a call to action, highlighting not only the broader systemic factors that widen the digital divide and make policy recommendations that accept the status quo unviable, but also the need to centre the student - rather than the institution, the teacher or technology - in future policy interventions and research.

Both these studies conclude that the global pandemic has exacerbated existing inequalities and the digital divide, confirming findings of some of the work already presented in our companion special issue, such as the international Delphi study on adult education by Bernd Käpplinger and Nina Lichte. ${ }^{2}$ The present studies from British Columbia and Pennsylvania also both convey a message of solidarity in a time of crisis and suffering. While highlighting the glimmers of hope, inventiveness and opportunity that opened up through the pandemic on which adult and community educators might build, both articles express concern about what the future might bring for adult education given the ongoing intensity of the crisis. Smythe, Wilbur and Hunter warn that "inventiveness will be undone, tamed, de-funded, co-opted", noting that it remains to be seen "what adult education might become in the wake of social isolation, digital exclusion and endless videoconferencing". Zukowski et al. worry about the "further destabilisation of the economy, and a new set of risks for educational and social life". The authors suggest that virtual learning will persist, as it "will seem a more viable route to programme managers in the future due to its low cost and scalability", yet they doubt that the shift to online learning will be beneficial for marginalised communities.

Some of the lessons for schools are drawn out by William C. Smith in his article "Consequences of school closure on access to education: Lessons from the 2013-2016 Ebola pandemic". He presents a very interesting and pertinent case study of the Ebola outbreak to exemplify the effect of school closures on school transition and dropout rates. Smith is particularly interested in the question of which students remain absent when schools resume following a crisis. Using data from the 2013-2016 Ebola outbreak in Guinea and Sierra Leone, the only health crisis in

\footnotetext{
${ }^{2}$ Käpplinger, B., \& Lichte, N. (2020). "The lockdown of physical co-operation touches the heart of adult education": A Delphi study on immediate and expected effects of COVID-19. International Review of Education, 66(5-6), 777-795. https://doi.org/10.1007/s11159-020-09871-w.
} 
the past century which is comparable in terms of the length and intensity of school closures to the current lockdown measures, he examines changes in enrolment and dropout patterns, with a particular focus on traditionally marginalised groups. His findings from his analysis of the Ebola data, which suggest that youth in the poorest households see the highest dropout rates, indicate that targeted support will be needed to prevent poor and marginalised students being left behind in the wake of the pandemic. This support, the author argues, should look well beyond the reopening of buildings to include comprehensive financial support packages for those groups most likely to be affected.

The fourth article of this issue also considers the impact on schools and schoolchildren. In "COVID-19 and the right to education in Chile: An opportunity to revisit our social contract", Denisse Gelber, Carolina Castillo, Luciano Alarcón, Ernesto Treviño and Rosario Escribano examine the consequences of school closures in Chile during the COVID-19 lockdown. Chile's education system is characterised by its strong market orientation and neoliberal policies that tend to (re)produce socio-economic inequalities. Educational reforms carried out between 2014 and 2017 aimed to mitigate some of these effects, albeit with mixed results. Against this background, the authors apply Katarina Tomasevski's 4-A scheme (availability, accessibility, acceptability and adaptability) to examine how the right to education has been upheld by the government in Chile during the pandemic and whether its policies have mitigated or exacerbated long-standing inequalities. The authors conclude that the country faces a major challenge in ensuring the right to education for all, largely because of educational segregation and structural inequalities in Chilean society, and they call for the creation of a new social contract guaranteeing this right to avoid the current crisis making existing inequalities still worse.

The need to find better ways to generate value and promote interaction with one another is at the heart of the next article, authored by Malak Zaalouk, Heba ELDeghaidy, Lamiaa Eid and Lujain Ramadan. In their article entitled "Value creation through peer communities of learners in an Egyptian context during the COVID19 pandemic", they emphasise the importance of collaboration and communities of practice in this time of crisis. The authors explore how teachers in Egyptian public schools have sought to mitigate the impact of the COVID-19 lockdown and school closures. The article focuses on a partnership between 43 schools and three faculties of education in universities that had built a community of practice through professional development effected in the context of an Erasmus+ initiative funded by the European Union. The authors show that the teachers who participated in this project were better prepared to deal with the emergency situation when it arose. A key finding of the study is that psychosocial support and relationships are very important for teachers in building up the resilience and skills that are needed to cope with a crisis of this sort.

The next four articles focus on higher education. Michelle Stack, in her article "Responding to the COVID-19 pandemic: University rankings or co-operatives as a strategy for developing an equitable and resilient post-secondary education sector?", offers another perspective on how we might learn the lessons of the pandemic and build something better and more equitable. She explores the appropriateness - or otherwise - of the current competitive ranking-based higher education system 
in dealing with the COVID-19 crisis. Building on her previous work on university rankings, she proposes the co-operatives model as an alternative strategy to develop a more equitable and resilient higher education system. She argues that, given the long-term effect COVID-19 is likely to have on higher education, the model of a cooperative with its focus on pooling resources and sharing expertise would be much more suitable than the current ranking and competition model, which tells us nothing about how universities are challenging or amplifying oppression in response to the pandemic, and is likely to make the distribution of resources still more inequitable. By contrast, the author's preferred model would put higher education institutions in a position to contribute to public debate and assume their responsibility to reconstruct education as a place of learning to live together in ways that provide the planet a chance at survival.

Kamal Raj Devkota, in his article "Inequalities reinforced through online and distance education in the age of COVID-19: The case of higher education in Nepal", draws on interviews with university executives, focus group discussions with university teachers and students and a review of strategic documents to examine the impact of the shift to online learning on university students in Nepal, where many have been forced to experience "displacement, disconnect and disengagement from formal learning". Devkota finds that while the promise of online learning is kept to some extent in the urban centres, it fails students from rural areas, low socio-economic backgrounds, and marginalised social groups, including women and Dalits, a minority group in Nepal. He argues that the shift to distance learning as a consequence of the COVID-19 pandemic lockdown has reinforced pre-existing social inequalities. Students living in poor or rural areas without access to the internet or the required access to digital equipment, and those lacking the technological or English language skills necessary to use some of these technologies, "were left behind, experiencing online teaching and learning as unreachable for them". The author recommends some strategies for universities to mitigate social inequalities, and urges the adoption of policies and practices that optimise the inclusive use of online and distance education programmes, both now and in the post-pandemic era.

These findings are strongly echoed by Nhlanhla Landa, Sindiso Zhou and Newlin Marongwe in their article, "Education in emergencies: Lessons from COVID-19 in South Africa". The authors examine the challenges arising for the rural student population in South Africa as teaching and learning shifted online learning following the announcement of lockdown in March 2020. The study draws on research involving educators and students from two universities in South Africa that predominantly serve students from rural areas. In their analysis of official university communications, the authors identify "gross inequalities" in terms of online teaching and learning outcomes among South African learners from different socio-economic backgrounds. The researchers note that the South African government failed to deliver on promises to provide laptops to rural students, while the lack of mobile network connectivity has proven to be a major obstacle to online learning in rural areas. Although universities did come up with numerous innovations to ensure continuity of learning, the authors conclude that these structural problems cast doubt on the future prospects of online learning in higher education, in particular for poor and rural students. 
The final article on universities, entitled "Educational disruptions during the COVID-19 crisis in Small Island Developing States: Preparedness and efficacy of academics for online teaching" also examines some of the challenges of the shift to online learning in universities. Isma Seetal, Sandhya Gunness and Viraiyan Teeroovengadum draw on a survey complemented by semi-structured interviews with a subsample of participants. Their study examines access, preparedness, and technology integration issues, as well as the impact of academics' leadership and institutional change management on the adoption of e-learning tools. The research team found that academic staff had often experienced difficulties in their efforts to shift to online teaching, the main reasons being slow internet connectivity and a lack of adequate training in the use of the technology. As a result, online teaching reflected an over-dependence on presentations, and a consequent underuse of other digital tools. The authors point to the important implications of these findings for the strategic planning of effective digital and online teaching and learning, arguing that these aspects need to be considered to ensure a sustained and sustainable effort from the academics, students, support staff and administrators alike in SIDS universities. In concluding, they identify some of the areas that require attention, including the cost implications for training and management of e-learning technologies and institutional autonomy and leadership, to ensure long-term change rather than shortterm continuity.

We conclude this double special issue with an article entitled "What are we saving? Tracing governing knowledge and truth discourse in global COVID-19 policy responses". Lynette Shultz and Melody Viczko offer a critical perspective on the role of technology in ensuring continuity of learning, a topic that has been at the top of the international agenda in education since the start of the pandemic and has generated a strong debate on the influence of private actors. Using Carol Bacchi's poststructural policy analysis and Miranda Fricker's notion of "epistemic injustice", the authors examine what they consider the underlying problematic logic driving three key norm-setting strategic interventions advanced by UNESCO, the Organisation for Economic Co-operation and Development (OECD) and the World Bank. All three organisations, Shultz and Viczko argue, present online education and digital technology as what they term "technologies of saving", in other words, as a panacea that can "save" education. The authors warn against the risk of epistemological injustice if "testimonies of saving are centred on privatised, corporate edu-tech aimed at online education delivery". This article offers a critical perspective on the role of international organisations and the idea that distance education alone represents a fair, inclusive or appropriate solution to the closing of schools and other educational institutions. We hope it will encourage further debate about alternative perspectives and future visions of education.

Determined in the context of a global emergency, the adoption of online learning as a last-resort solution raises a number of issues, among them the reinforcement of existing inequalities. This is the overwhelming message of most of the contributions in this special issue. In addition, a number of other important themes emerge from this collection of articles. These include the ability of children to learn without being in school. The de facto closure of education systems displaced the core of the teaching/learning process from schools to home environments, with the distant 
support of teachers, enabled by technology, and the active involvement of parents and guardians. This raised the question of what other forms education might take outside school and formal learning environments. Have we rushed towards technology-driven solutions at the cost of more community-based approaches? As Shultz and Viczko ask in their analysis: "What alternatives might be present in local contexts for children to learn?" The question of what we can take from this experience in imagining education in a post-pandemic society, not only for children, but also for adults and higher education students, is inherent in many of the articles, both here and in the companion special issue.

Another common theme is that the pandemic, and responses to it, have affected systems that were unprepared to deal with the current crisis. Reasons for this include that they had already been weakened by pre-existing inequalities, budget constraints and austerity measures. These were, in many cases, exacerbated by neoliberal policies aimed at reducing public spending and promoting markets and competition, often at the cost of democratic accountability. The adult education community and youth education sector in Canada and the United States, the market-oriented education system in Chile, and competitive ranking-based higher education systems provide illustrations of this amplification effect. In Nepal, in South Africa and in Small Island Developing States, the move to distance learning reinforced pre-existing socio-economic inequalities. Furthermore, South African universities were already struggling to make up for lost time before the crisis hit, due to persistent student protests. In Egypt, professional development and relationship-building enabled by EU funds helped to mitigate the pressures on teachers and schools for the group that was a part of the project, suggesting that schools and teachers who did not have access to extra training and funds were less prepared to deal with the crisis. These insights oblige us to reflect seriously on how to make our education systems fairer, better resourced and more resilient.

We would like, finally, to thank all the contributors to this special issue and all those who have been involved in putting it together. We believe that we speak for our authors when we express our hope that, as researchers, scholars and practitioners, we must find ways to collaborate in order to document, examine and discuss current developments around the world and their consequences for education and learning. We welcome submissions and special issue proposals that will take these debates further.

Publisher's Note Springer Nature remains neutral with regard to jurisdictional claims in published maps and institutional affiliations.

Paul Stanistreet $\mathrm{PhD}$, is Head of Knowledge Management and Communications at the UNESCO Institute for Lifelong Learning (UIL) in Hamburg and Executive Editor of the International Review of Education - Journal of Lifelong Learning (IRE). He has worked in education policy, research and advocacy for almost 20 years, including for the National Institute of Adult Continuing Education (NIACE) in the UK. He edited NIACE's journal, Adults Learning, from 2002 to 2014, and has published a blog on adult education - https://thelearningage.wordpress.com/ - since 2012. His early work background was in 
newspaper journalism, after which he studied philosophy as a mature student. He gained his PhD from the University of Glasgow in 1999.

Maren Elfert $\mathrm{PhD}$, is Lecturer in Education \& Society in the School of Education, Communication and Society at King's College London, and a 2018 National Academy of Education/Spencer Postdoctoral Fellow. Before pursuing doctoral studies, she worked for more than a decade as a member of the professional staff at the UNESCO Institute for Lifelong Learning (UIL) in Hamburg, Germany. In 2020, she joined the editorial team of the International Review of Education - Journal of Lifelong Learning (IRE) as Submissions Editor. Her research focuses on global governance of education and the influence of international organisations on educational ideas and policies.

David Atchoarena is Director of the UNESCO Institute for Lifelong Learning (UIL) in Hamburg, Germany. He was appointed in April 2018. He was previously Director of the Division for Policies and Lifelong Learning Systems at UNESCO, including Policy, Higher Education, Technical and Vocational Education and Training (TVET) and Technology in Education. Prior to working for UNESCO, including many years at the International Institute for Educational Planning (IIEP) as programme specialist and later as Team leader, Mr Atchoarena served as Chargé de Mission at the National Agency for Lifelong Education (ADEP) of the French Ministry of Education and as project coordinator in the Ministry of Finance and Planning in Saint Lucia. He holds a doctorate in Economics from the University of Paris I (Panthéon-Sorbonne). 